\title{
An uncertainty and sensitivity analysis applied to the prioritisation of pharmaceuticals as surface water contaminants from wastewater treatment plant direct emissions
}

\author{
Sérgio Alberto Morais ${ }^{a, b}$, 国, Cristina Delerue-Matos ${ }^{b}$, Xavier Gabarrell $^{a, c}$ \\ a SosteniPrA (UAB-IRTA-Inèdit), Institut de Ciència i Tecnologia Ambientals (ICTA), Universitat Autònoma de Barcelona (UAB), \\ 08193 Bellaterra, Barcelona, Spain \\ b REQUIMTE, Instituto Superior de Engenharia do Porto, Instituto Politécnico do Porto, Rua Dr. António Bernardino de Almeida, \\ 4200-072 Porto, Portugal \\ C Departament d'Enginyeria Química, Escola d'Enginyeria, Universitat Autònoma de Barcelona (UAB), 08193 Bellaterra, \\ Barcelona, Spain
}

\begin{abstract}
In this study, the concentration probability distributions of 82 pharmaceutical compounds detected in the efflu- ents of 179 European wastewater treatment plants were computed and inserted into a multimedia fate model. The comparative ecotoxicological impact of the direct emission of these compounds from wastewater treatment plants on freshwater ecosystems, based on a potentially affected fraction (PAF) of species approach, was assessed to rank compounds based on priority. As many pharmaceuticals are acids or bases, the multimedia fate model accounts for regressions to estimate $\mathrm{pH}$-dependent fate parameters. An uncertainty analysis was performed by means of Monte Carlo analysis, which included the uncertainty of fate and ecotoxicity model input variables, as well as the spatial variability of landscape characteristics on the European continental scale. Several pharma- ceutical compounds were identified as being of greatest concern, including 7 analgesics/antiinflammatories, $3 \beta$-blockers, 3 psychiatric drugs, and 1 each of 6 other therapeutic classes. The fate and impact modelling relied extensively on estimated data, given that most of these compounds have little or no experimental fate or ecotoxicity data available, as well as a limited reported occurrence in effluents. The contribution of estimated model input variables to the variance of freshwater ecotoxicity impact, as well as the lack of experimental abioticdegradation data for most compounds, helped in establishing priorities for further testing. Generally, the effluent concentration and the ecotoxicity effect factor were the model input variables with the most significant effect on the uncertainty of output results.
\end{abstract}

Keywords: Pharmaceuticals, Multimedia fate model, Freshwater ecotoxicity, lonisable organics, Uncertainty analysis, Wastewater treatment plants

\section{Introduction}

The presence of pharmaceuticals in the environment and their potential to induce adverse biological effects have been known for many years (Aherne and Briggs, 1989; Tabak and Bunch, 1970). The

most common environmental contamination pathways are the emis- sion of pharmaceutical compounds from wastewater treatment plants (WWTPs) and the application of livestock manure as a top soil dressing (without previous wastewater treatment). Livestock manure contains veterinary drugs that are likely to contaminate the soil and ground- water, which, after rainfall incidents, can reach surface waters from contaminated soil by run-off. The main sources of emission for these environmental contamination pathways are the urinal and faecal excre- tion products of medically treated human and animals. Other less important sources of contamination include industrial wastewater and drugs disposed of with domestic waste in landfill sites, which 

could lead to groundwater contamination by leaching (Ternes, 1998). The pathways of contamination after excretion and passage through municipal sewage systems include the infiltration of sewage from leak- ages in drains, the application of biosolids from WWTPs on agricultural areas and landscapes, and, due to incomplete removal, the disposal of WWTP effluents and raw sewage into surface waters and as reclaimed water into agricultural fields and landscapes by irrigation. Regarding these emission pathways from WWTPs, we distinguish between direct and indirect emissions to the freshwater compartment. The application of biosolids and effluents into agricultural soils and landscapes can also lead to the migration of contaminants to surface waters via run-off (Borgman and Chefetz, 2013; Sabourin et al., 2009); therefore, such emissions are defined here as indirect emissions to freshwater.

Although much research has been conducted on the topic of direct emissions of pharmaceuticals from WWTPs, past studies examining the prioritisation of pharmaceuticals (e.g., Besse and Garric, 2008; Christen et al., 2010; Sanderson et al., 2004) do not account for spatial variations of the environmental landscape, or include a comprehensive uncertainty and sensitivity analysis of the results when most of fate and impact data are estimated, nor do most of them account for the ionising properties of pharmaceuticals when most of these compounds are acids or bases.

The aim of this study is to prioritise pharmaceutical compounds from WWTP direct emissions in their impact to freshwater ecosystems, identifying gaps of knowledge and relevant fate and impact issues in order to establish topics for further research. To provide a holistic view of the pharmaceuticals of greatest concern, we collected data concerning pharmaceutical occurrence in 179 WWTPs in Europe. A multimedia model representing the European continental scale was applied to prioritise pharmaceuticals according to their probabilistic impact on freshwater ecosystems, computed by means of Monte Carlo analysis, from WWTP direct emissions. Generally, experimental fate input variables, such as partitioning coefficients or degradation rates, and ecotoxicity data are scarce for most pharmaceuticals; therefore, estimation methods must be applied in an assessment. Research topics on monitoring in WWTP effluents, degradation in the environment or in ecotoxicology effects were prioritised for the compounds ofmost concern by indentifying important gaps of knowledge, as well as by computing the contribution of estimated model input variables' uncertainty and variability to the impact variance. Currently, a similar assessment is being performed for indirect emissions to the freshwater compartment.

The multimedia model USEtox (Rosenbaum et al., 2008) was chosen as the basis for this comparative impact assessment because it results from a consensus building effort, under the auspices of UNEP and SETAC, amongst modellers; hence, its underlying principles reflect common and agreed recommendations from these experts. In compar- ative impact assessment methodologies, the conversion of emissions to ecotoxicological impacts comprises a fate and an effect analysis step (van Zelm et al., 2007). The fate factor describes the marginal increase in environmental concentration per unit of emission. The ecotoxicity effect factor (EEF) addresses the marginal increase in effect (toxic pressure on ecosystems) per unit of chemical concentration. An assess- ment factor (AF) based on the predicted no effect concentration (PNEC) approach is recommended in generic risk assessment according to the TGD (EC, 2003); however, a potentially affected fraction (PAF) of species approach based on the average toxicity was considered in the present study as a basis for the EEF calculation, as adopted in the USEtox model. Both approaches have advantages and drawbacks (Larsen and Hauschild, 2007a,b); however, a PAFbased approach has two main ad- vantages that better serve the purposes of this study: 1) a PNEC ap- proach targets the protection of the most sensitive species; therefore, the risk of bias is high when scarce ecotoxicity data are available, which is the case for pharmaceuticals; and 2) the assessment of the mean impact (AMI) on ecosystem method, a PAF-based approach, allows the quantification of uncertainty, giving an indication of the 
reliability of the results. The AMI method is based on the hazardous con- centration (HC) at which the effect concentration (with an endpoint of, for example, mortality) affecting $50 \%$ of tested individuals (EC50) is exceeded for $50 \%$ of the included species; this is also called HC50EC50 (Payet, 2004, 2005; Payet and Jolliet, 2005). Two statistical estimators can be used to estimate the toxicity of a substance to biological species and the associated confidence interval: a non-parametric estimator using the median as the HC50EC50 combined with bootstrap statistics to estimate its uncertainty (Payet and Jolliet, 2005) or a parametric estimator based on the assumption of a lognormal distribution of data using the geometric mean as HC50EC50 and Student's t-statistics for its confidence interval (Payet, 2004, 2005).

\section{Methodology}

\subsection{Emission data}

A survey of the occurrence of pharmaceuticals in the effluents of European WWTPs was performed to compute concentration probability distributions. The survey is based on a recent review conducted by Verlicchi et al. (2012) on the global occurrence of pharmaceuticals in urban wastewater. For this Europe-focused study, 54 peerreviewed publications were identified from the cited review covering 179 WWTPs located in Austria, Denmark, Finland, France, Germany, Greece, Italy, Spain, Sweden, Switzerland, and the UK, with capacities ranging from 6000 to 2500000 population equivalents. Effluent con- centration data included 82 drugs pertaining to 15 different classes: 19 analgesics/anti-inflammatories (including 1 metabolite), 15 antibi-

otics, $12 \beta$-blockers, 7 psychiatric drugs, 7 lipid regulators (including 2

metabolites), 4 hormones, $4 \quad \beta$-agonists, 3 receptor antagonists, 3 anti-

neoplastics, 2 antihypertensives, 2 diuretics, 1 proton-pump inhibitor, 1 antiseptic, 1 contrast agent, and 1 antifungal (Supplementary data, Table S3). The quality of effluent concentration data reported in the lit- erature has been confirmed according to the EC Technical Guidance Document (TGD) on Risk Assessment (EC, 2003). Therefore, the refer- ences included in the survey feature a description of the analytical methodology and the quality assurance programme used for sampling, analysis and elaboration. Considering only WWTPs with data available on population served (number of the inhabitants in the catchment), the effluent concentration in each WWTP was weighted by the popula- tion served and the geometric mean and the geometric standard devia- tion of the effluent concentration, in $\mathrm{mg} / \mathrm{l}$, in European WWTPs were computed. Aggregated data on a compound concentration in several WWTPs effluents were weighted using the aggregated data on population served. The probability distribution, assuming a lognormal distribu- tion, of the effluent concentration of each compound was used as input into a multimedia fate and transport model, assuming steady-state con- centrations, to assess the comparative impact to freshwater ecosystems.

\subsection{Fate modelling}

Fate factors describing the marginal increase in environmental concentration of pharmaceuticals per unit of emission were computed by a model based on the multimedia model USEtox (Rosenbaum et al., 2008) and described in detail in Morais et al. (2013a,b). The difference between models refers to the inclusion of regressions to estimate $\mathrm{pH}$ dependent fate parameters if no suitable experimental values are avail- able, such as the solid-water partitioning coefficient normalised by the organic carbon, KOC (Franco and Trapp, 2008) and the bioconcentration factor in fish, BCFfish (Fu et al., 2009). Over $60 \%$ of pharmaceuticals are acids or bases that are fully or partially dissociated at environmental $\mathrm{pH}$ (Avdeef, 2003); hence, conventional non-polar regressions cannot be applied without considering the ionisation of pharmaceuticals (Escher et al., 2011; Tarazona et al., 2010). For the environmental compartments evaluated, the landscape characteristics of the USEtox European continental scale were applied. The fate model accounts 


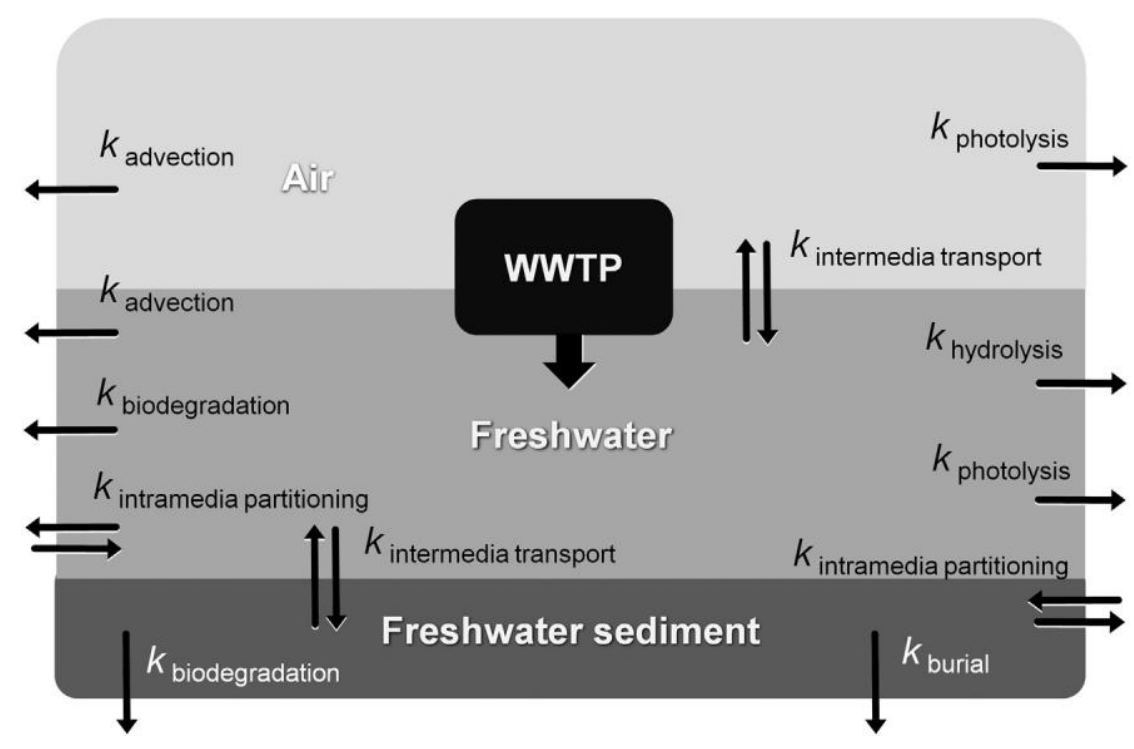

Fig. 1. Three-compartment system for the dissipation of pharmaceuticals from direct emissions to freshwater of WWTP effluents.

for inter-media transport processes, intramedia partitioning and degradation in the environment (Fig. 1) and is further described in Supplementary data, sections S1 and S2.

Abiotic degradation mechanisms in the freshwater compartment are important elimination processes for pharmaceuticals (Andreozzi et al., 2003; Doll and Frimmel, 2003). However, the USEtox model does not address estimation procedures for these mechanisms; therefore, to estimate direct and indirect photodegradation rates, a number of models and assumptions were applied and are described in detail in Morais et al. (2013a,b). A short description is provided in Supplementary data, section S2.

\subsection{Ecotoxicity effect factor}

The EEF indicator, i.e., $0.5 / \mathrm{HC5OEC5O}$, in PAF $\mathrm{m}^{3} \mathrm{~kg}^{-1}$, focuses on the trophic structure by including the EC50 values of at least 3 trophic levels: primary producers (algae), primary consumers (crustaceans),

and secondary consumers (fish) (Supplementary data, Table S5). The low environmental concentrations but constant introduction to the en- vironment indicate that pharmaceuticals are more likely to have chronic rather than acute toxic effects on aquatic biota (Carlsson et al., 2006; Fent et al., 2006; Quinn et al., 2008); hence, chronic EC50 values are pre- ferred as well as, due to the comparative context of the assessment, standard tests/test conditions and standard test organisms. However, the ecotoxicological data on pharmaceuticals remain scarce, and there are not enough chronic experimental ecotoxicity data available to perform an assessment (Escher et al., 2011). An acute-chronic ratio of 2 was applied to extrapolate chronic HC50EC50 values from acute HC50EC50 values, as recommended by Larsen and Hauschild (2007b), and was applied in the USEtox model
(Huijbregts et al., 2010). However, the best estimate AFs for this extrapolation have not yet been devel- oped, and research is needed in this area (Larsen and Hauschild, 2007b), particularly in the context of micropollutants. Even acute ecotoxicity data are only available for a very limited set of pharmaceuti- cals (Escher et al., 2011); therefore, EC50 values are completed by extrapolation from the lowest observed effect concentration (LOEC) or no observed effect concentration (NOEC) values, according to the best-estimate AFs from Payet (2004). To determine missing experimen- tal data, quantitative-structure activity relationship (QSAR) data were included using the software programme ECOSAR v1.00 (Nabholz and Mayo-Bean, 2009). For estimated data, a conservative approach was followed by considering the chemical class with the highest potency (i.e., the lowest concentration predicted to cause the toxic effect), 
except in the case of the neutral organics class if a compound is completely dissociated at environmentally relevant $\mathrm{pH}$ values.

The baseline toxicity, or narcosis, is the addressed toxic mode of action (TMoA) in most generic risk assessment or impact assessment methodologies. Previous studies have shown that most pharmaceuticals produce their environmental adverse effect via narcosis (Sanderson and Thomsen, 2007). However, some pharmaceuticals, which are designed to be bioactive (with the exception of contrast agents), also exhibita therapeutic effect in non-target aquatic life, such as the estrogenic effects caused by hormones in fish (Santos et al., 2010), or they act via a specific TMoA, such as the inhibition of photosynthesis caused by $\beta$-blockers in algae (Escher et al., 2006). As a change in sex ratio appar- ently relates directly to the reproduction of a fish population, this endpoint is considered more relevant than vitellogenin in an impact assessment context (Larsen et al., 2010). Hence, the endpoints used for the average toxicity calculation include the inhibition of growth and photosynthesis for algae, mortality or immobility (Daphnia) forinvertebrates, and mortality or change in sex ratio for fish.

\subsection{Uncertainty and sensitivity analysis}

The propagation of the uncertainty and variability of model input variables in the output results was quantified by Monte Carlo analysis. The model output is the ecotoxicity impact on freshwater, in

PAF $\cdot \mathrm{m}^{3} \mathrm{~d}$. The parameters included in the analysis are described in the Supplementary data, Table S6. The analysis includes the following

factors:

(1) The variability of effluent concentrations, direct photolysis rates (kphoto, fw) and continental-scale environmental parameters (freshwater $\mathrm{pH}$, rainfall, freshwater concentration of suspended matter, dissolved organic carbon, and ${ }^{\bullet} \mathrm{OH}$ ). For each pharmaceu- tical, the maximum and minimum of the uniformly distributed photodegradation rate parameter were obtained considering results for the winter and summer seasons, the latitudes of 40 and 60 , and experimental quantum yields (see Supplementary data, section S2)

(2) The uncertainty of the EEF. Uncertainty distributions of HC50EC50 values were estimated according to the parametric estimator, as recommended by Payet (2004). Moreover, the parametric esti- mator is based on the geometric mean, which is the most robust average estimator for HC50EC50 (Larsen and Hauschild, 2007b). However, the uncertainty of extrapolating average chronic 
toxicity, i.e., chronic HC50EC50, from average acute toxicity was not addressed in the present study, nor was the uncertainty of extrapolating and estimating individual endpoints.

(3) The uncertainties associated with the regression equations adopted in the model to estimate partition coefficients ( $\mathrm{OOC}$ and $\mathrm{KOW}$ ), bioconcentration factors in fish (BCFfish) and bio- transformation rates ( $k$ bio, $\mathrm{fw}$ ). The procedure to compute the un-certainty descriptors of regressions equations is described in detail in Morais et al. (2013a,b). In short, the training and valida- tion sets used to derive the regression methods applied in the present study (Franco and Trapp, 2008; Fu et al., 2009; USEPA, 2008a, 2009) were used to derive mean residual errors and their uniformal distributions and were fit into the regressions.

(4) The uncertainty associated with experimental parameter values (partition coefficients, biotransformation halflives, and $\mathrm{kOH}$ ).The geometric mean and the geometric standard deviation of experimental values were set as uncertainty descriptors, assum- ing a lognormal distribution.

The identification of relevant parameters to the impact variance, performed by a sensitivity analysis, enables setting research priorities. The contribution to the variance provides an approximation of the per- centage of the variance or uncertainty of an output result caused by the variability or uncertainty of a given model parameter. The contribution was calculated by squaring the correlation coefficients between model input variables and impact results, for a given number of trials, and normalising them to $100 \%$.

\section{Results and discussion}

Fig. 2 shows the comparative ecotoxicological impact of pharmaceu- ticals emitted directly from WWTP effluents to the freshwater compart- ment. In order to rank compounds for further discussion the contribution of each pharmaceutical's uncertainty to the variance of total ecotoxicity was calculated. A general condition for impact assessment methodolo- gies is that the impact indicator be additive (Larsen and Hauschild, 2007b); however antagonisticsynergistic interactions in mixtures of pharmaceuticals are not accounted for in such approaches. The total ecotoxicity impact is $6.51 \times 10^{-2}$ PAF m $\mathrm{m}^{3} \mathrm{~d}$ per $\mathrm{m}^{3}$ of effluent (95\% con-fidence interval $\left.=2.84 \times 10^{-2}-6.61 \times 10^{-1}\right)$. The contribution of each pharmaceutical's uncertainty to the variance of total ecotoxicity can be computed; these results are shown in Fig. 3. It is assumed that the phar- maceuticals of most concern are those totalling a $90 \%$ contribution to the total impact variance. For the pharmaceuticals of most concern, the con- tribution of model input variables to the variance of the results of Fig. 2 is shown in Fig. 4. Generally, for the substances of most concern, the HC50 parameter is the most relevant one for the statistical spread of impact re- sults shown in Fig. 2. For most substances, the parametric quantification of $\mathrm{HC} 50$ uncertainty is based on only 3 data values, which typically pro- duces wide confidence limits (Larsen and Hauschild, 2007a), making the statistical differentiation between substances ambiguous. Compounds of most concern are further discussed by dividing the most relevant therapeutical classes into sections.

\subsection{Antineoplastics}

The antineoplastic tamoxifen displays the highest median ecotoxicity impact (Fig. 2). The uncertainty of the HC50 parameter contributes $93.8 \%$ of the variance of the tamoxifen impact results (Fig. 4). Only 2 experimen- tal acute EC50 values, covering 1 trophic level, were obtained in the present study (Supplementary data, Table S5). The ecotoxicological datum on algae was estimated by ECOSAR. The quantification of this QSAR method's uncertainty is not considered in the present study, as stated in Section 2.4; therefore, its influence on impact results is unclear. In addition, the EC50 value for crustaceans was extrapolated from the NOEC. The inherent uncertainty of extrapolating ecotoxicological endpoints is also not considered in the present study. Overall, a more comprehensive ecotoxicological study is needed. Moreover, the 


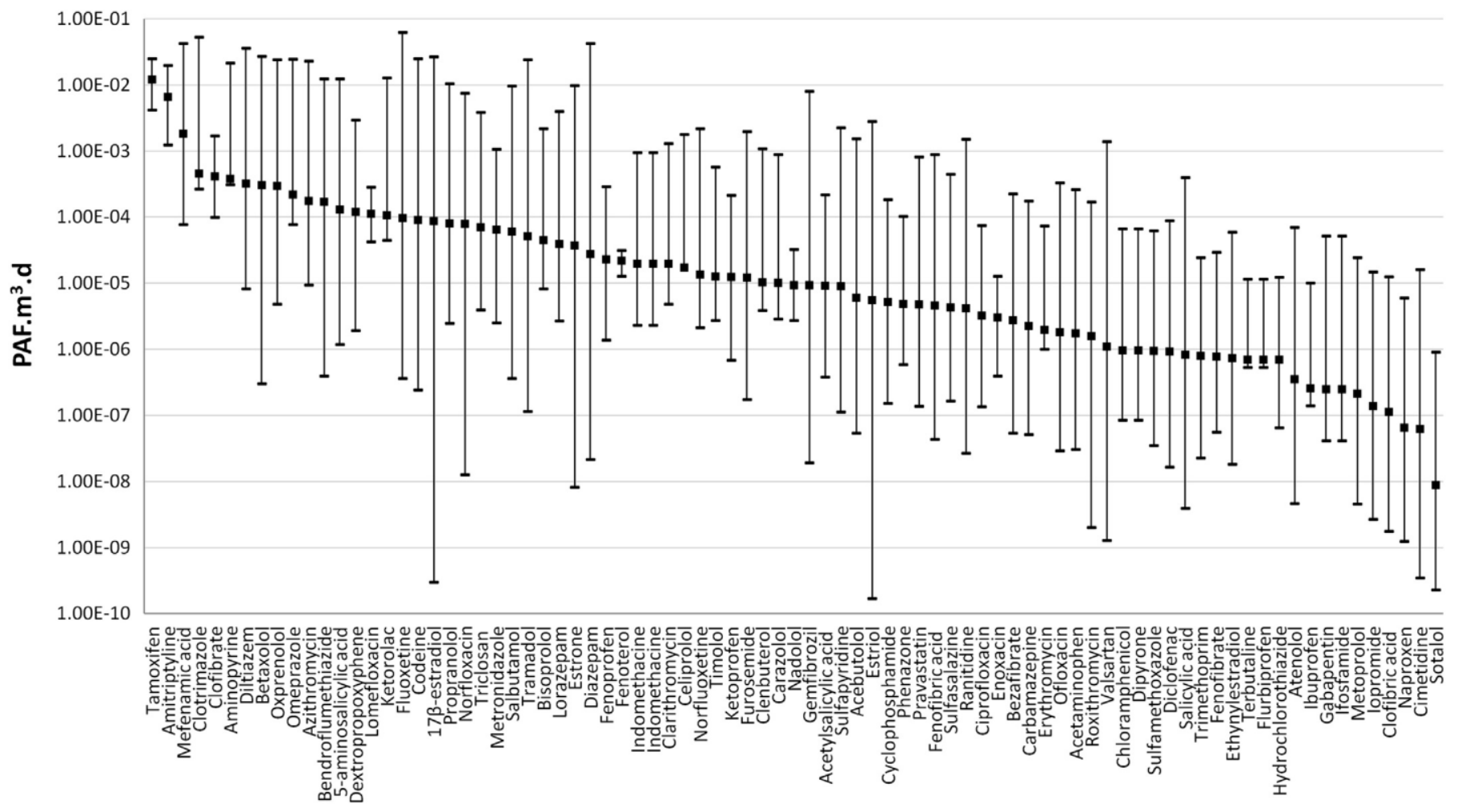

Fig. 2. Probability distribution median and $95 \%$ confidence interval of ecotoxicity impact, in PAF $m^{3} d$, of pharmaceuticals on freshwater per $\mathrm{m}^{3}$ of WWTP effluent. 


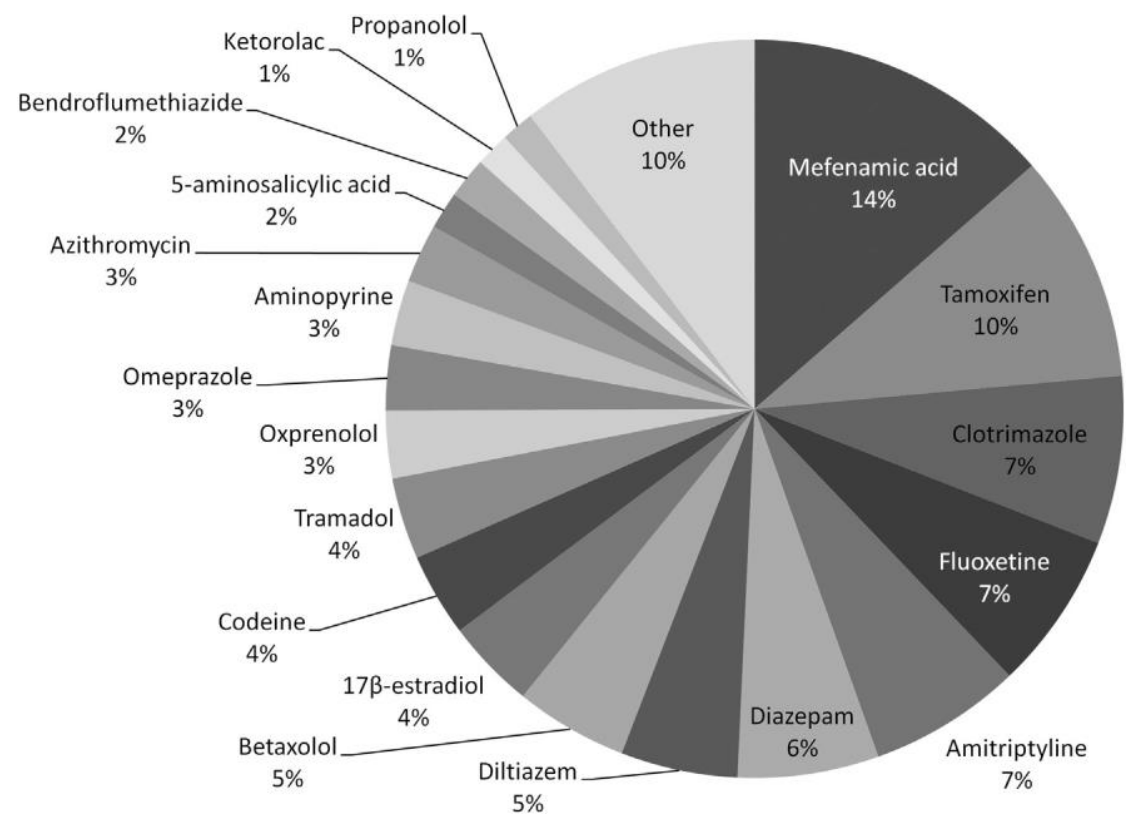

Fig. 3. Contribution to variance of total freshwater ecotoxicity impact.

calculated impact of tamoxifen is based on very limited data on measure- ments in WWTP effluents (e.g., Roberts and Thomas, 2006) According to the outcome of the present study, tamoxifen should be subject to moni-toring in WWTP effluents for more conclusive results. The neutral form of tamoxifen, with an estimated log KOW of 6.30 (USEPA, 2008b), is highly hydrophobic. Moreover, tamoxifen is predominantly found in the basicform at $\mathrm{pH} 7(\mathrm{pKa}=8.52)$; therefore, electrostatic interactions may play a significant role in its partitioning into negatively charged sorption sites of particles and, consequently, in its removal from WWTPs. The environmental occurrence of tamoxifen is, however, common (e.g., Hilton and Thomas, 2003; Roberts and Thomas, 2006; López-Serna et al., 2012). Another issue of concern, and a subject for further study, is the depletion of tamoxifen, which may be underestimated in the aquatic environment because no data on indirect photolysis are available in the literature, such as bimolecular rate constants for the reaction between the compounds and chemical transients. This compound, which has double bonds and aromatic rings, may react with chemical transients generated by natural water constituents under sunlight, especially with 


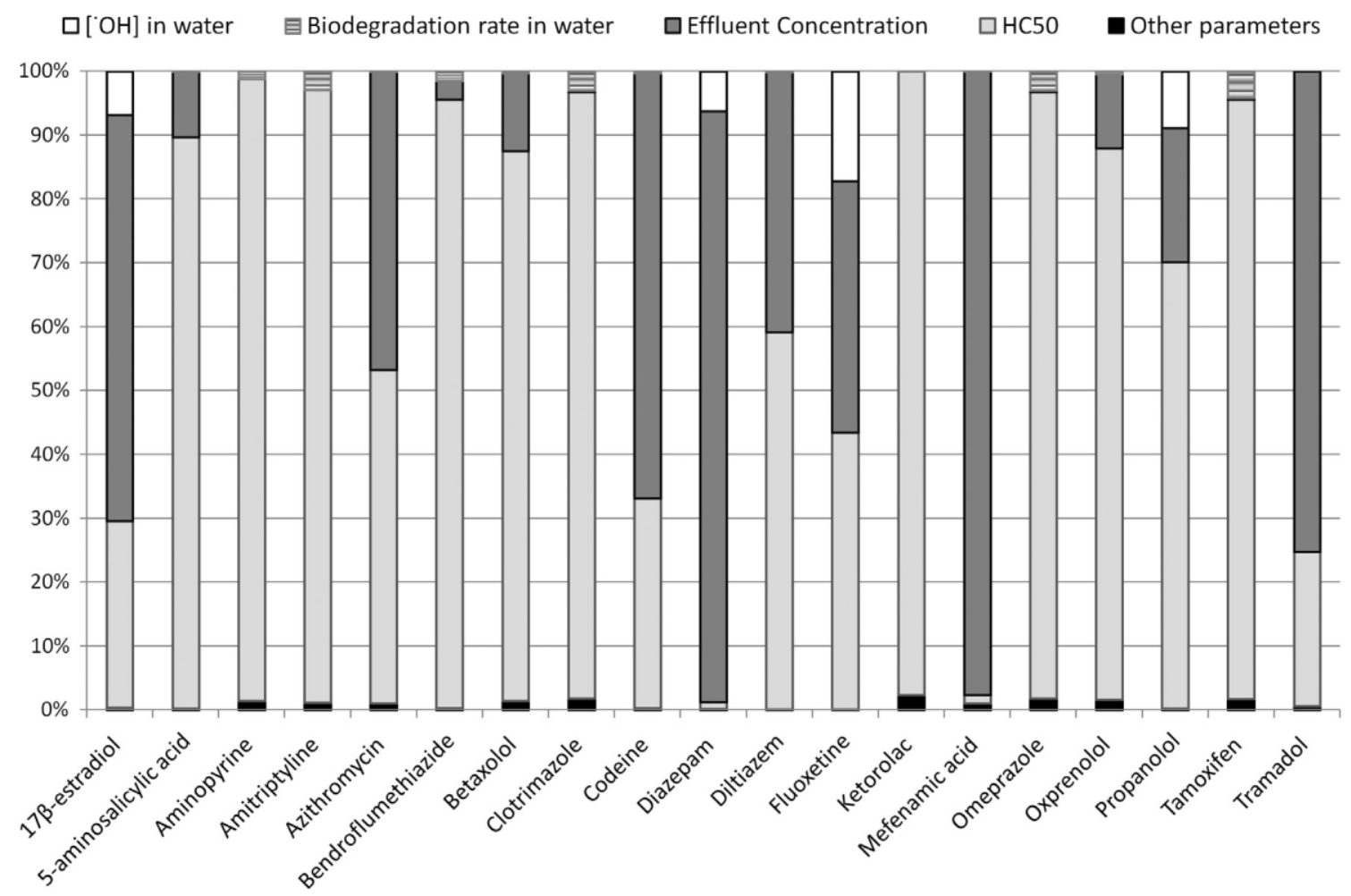

Fig. 4. Contribution of model input variables to impact variance of pharmaceuticals of most concern. 
the extremely reactive hydroxyl radical that can abstract hydrogen from saturated organics, add to double bonds or add to aromatic rings. In contrast, the chronic ecotoxicity of tamoxifen derivatives produced by direct photolysis revealed no significant differences in comparison to the parental compound (DellaGreca et al., 2007); therefore, the overall impact of tamoxifen may be underestimated, given that photoproducts were not included in the present study.

\subsection{Analgesics/anti-inflammatories}

Mefenamic acid is a widely used non-steroidal antiinflammatory compound and is commonly found in WWTP effluents (e.g., Barron et al., 2009; Radjenovic et al., 2009; Rosal et al., 2010; Tauxe-Wuersch et al., 2005). Literature data on mefenamic acid concentrations in WWTP effluents vary by 3 orders of magnitude, from 0.005 (KasprzykHordern et al., 2009) to $3.0 \mu \mathrm{g} / \mathrm{l}$ (Tauxe-Wuersch et al., 2005). The variability of the effluent concentration contributes $97.7 \%$ of the variance of the impact of mefenamic acid (Fig. 4). However, the calculated effect of this anti-inflammatory may be overestimated, given that Werner et al. (2005) suggested that photosensitisation by ex- cited triplet-state DOM may contribute to the environmental degrada- tion of mefenamic acid. The influence of this degradation mechanism on the calculated effect remains unknown in the present study.

The calculated impact of aminopyrine is based on estimated ecotox- icological data. Even excluding the uncertainty of ecotoxicity data estimation, the HC50 parameter has a contribution of $97.4 \%$ to the vari- ance of the impact of aminopyrine. Moreover, this compound is not commonly detected in WWTP effluents (e.g., Ternes, 1998; Andreozzi et al., 2003). Poor sorption to particles in WWTPs may be expected, given that the predominant neutral form of this basic compound at $\mathrm{pH} 7(\mathrm{pKa}=5.0)$ has an estimated log KOW of 0.6 (USEPA, 2008b). There- fore, depending on the role of its biotransformation in WWTPs, a very low influent concentration or non-existent discharge may have been observed in WWTPs; nevertheless, no data on influent concentrations were reported in the literature. In fact, the human clinical use of amino- pyrine is widely banned due to the risk of agranulocytosis and due to its potential to produce carcinogenic nitrosamines (U.N., 2003); hence, its presence in WWTP discharges may be caused by low levels of appli- cation in veterinary medicine or by industrial release (Ternes, 1998). No abiotic degradation data are available; however, aminopyrine is ex- pected to be susceptible to indirect photolysis. In addition, it contains chromophores that absorb at wavelengths $\mathrm{N} 290 \mathrm{~nm}$ and may therefore also be susceptible to direct photolysis; hence, the residence time of aminopyrine in the aquatic environment may be overestimated.

The concentration reported in the literature on the occurrence of the opiate codeine in WWTP effluents varies by 3 orders of magnitude (Gómez et al., 2007; Wick et al.,
2009), from 0.022 to $15.59 \mu \mathrm{g} / \mathrm{l}$. This variability of the effluent concentration contributes $66.6 \%$ of the variance of impact results. The HC50 parameter contributes $32.8 \%$; furthermore, estimated data were applied and, as stated above, the quantification of uncertainty in endpoints estimation was not consid- ered in the present study; therefore, the influence of using estimated data on impact variance is unclear. Codeine is expected to be susceptible to indirect photolysis and contains chromophores that absorb at wavelengths N $290 \mathrm{~nm}$; therefore, it may also be susceptible to direct photolysis.

The concentration of tramadol in WWTP effluents reported in the literature varies by 3 orders of magnitude, from 0.02 to $97.62 \mu \mathrm{g} / \mathrm{l}$ (Kasprzyk-Hordern et al., 2009; Wick et al., 2009). The effluent concen- tration of tramadol contributes $75.3 \%$ to the impact variance. The HC50 parameter represents $24.1 \%$ of the tramadol impact result variance; fur- thermore, for experimental EC50 values of 2 trophic levels, crustaceans and fish, the species were not specified in the literature. In terms of environmental occurrence, tramadol was detected in 2 rivers in South Wales, UK at a maximum concentration of $5970 \mathrm{ng} / \mathrm{l}$ (KasprzykHordern et al., 2009). 


\section{3. $\beta$-Blockers}

The HC50 parameter contributes between 70 and $86 \%$ to the impact results for variance of the $\beta$-blockers betaxolol, oxprenolol, and propanolol. Moreover, oxprenolol ecotoxicity data have been estimated for all trophic levels, and in the case of betaxolol, only 1 acute EC50 value is experimental. Propanolol is commonly measured in WWTP effluents (e.g., Alder et al., 2010; Maurer et al., 2007; Wick et al., 2009); however, limited data are available on the occurrence of oxprenolol and betaxolol in WWTP effluents (Ternes, 1998; Andreozzi et al., 2003). According to the molecular structures of $\beta$-blockers, indirect photolysis may play a role in their persistence in the aquatic environment; however, except for propanolol, no experimental data on photosensitisation were found in the literature; therefore, its residence time in the aquatic envi- ronment may be overestimated. In fact, in terms of environmental occurrence, no literature data on oxprenolol were found; however, betaxolol was not detected in 29 rivers in Germany, even when it was present in WWTP effluents (Ternes, 1998), nor was it detected in the Ebro River in Spain (López-Serna et al., 2012).

\subsection{Psychiatric drugs}

In addition to the high contribution of the HC50 parameter to the variance impact of the tricyclic antidepressant amitriptyline (95.9\%), the experimental ecotoxicological data were limited to crustaceans, with chronic EC50 values for 4 species. In the case of other trophic levels, ECOSAR values were applied. Both the high sorption potential of the neutral form, with an estimated log KOW of 4.95 (USEPA, 2008b), and the predominance of the basic form at $\mathrm{pH} 7(\mathrm{pKa}=9.4)$ indicate signif- icant removal in WWTPs. Nevertheless, the literature data (both on measurements of amitriptyline in WWTP effluents and on the fate of amitriptyline in WWTPs) are too limited for conclusive results. In addition, according to its molecular structure, amitriptyline may be sus- ceptible to indirect photolysis; hence, its residence time in the aquatic environment may be overestimated in the present study.

The impact of diazepam is comparatively significant for the higher concentrations in WWTP effluents that have been reported in the liter- ature (Supplementary data, TableS3). This parameter has a contribution of $92.5 \%$ to the impact variance. The concentration ranges 3 orders of magnitude, from 0.04 to $19.3 \mu \mathrm{g} / \mathrm{l}$ (Suárez et al., 2005; Ternes, 1998); however, measurements of this compound in WWTP effluents are very scarce in the literature.

The HC50 parameter contributes $43.3 \%$ to impact variance of the se- rotonin reuptake inhibitor fluoxetine. Three acute experimental HC50s covering 3 trophic levels were applied. An acute LC50 value was applied for fish; however, for fluoxetine, other TMoAs such as endocrine disrup- tion may be relevant, given that Mennigen et al. (2008) suggested that fluoxetine may have the potential to affect sex hormones and modulate genes involved in the reproductive function of fish. The effluent concen- tration has a contribution of $39.4 \%$ to the impact variance. Although direct photolysis could potentially limit the persistence of fluoxetine in surface waters, Lam et al. (2004) suggested that its degradation by indirect photolysis would be the limiting degradation mechanism.

\subsection{Other therapeutical classes}

The statistical spread of the antifungal clotrimazole's impact is also mainly due to the HC50 parameter, with a $95 \%$ contribution to the variance. According to its molecular structure, clotrimazole is expected to be susceptible to indirect photolysis; therefore, its residence time in the aquatic environment may be overestimated. The neutral form of clotrimazole, which predominates at $\mathrm{pH} 7(\mathrm{p} K \mathrm{a}=5.22)$, is highly hy- drophobic, with an estimated log KOW of 6.26 (USEPA, 2008b); there- fore, significant partitioning to particles in WWTPs may be observed. There are limited data on the occurrence of this topical product in WWTP effluents at detectable concentrations (OSPAR, 2005); however, 
clotrimazole is a widely used over-the-counter antifungal agent. More- over, in terms of environmental occurrence, clotrimazole was the most frequently detected of 14 pharmaceuticals analysed in UK estuaries, with median concentration of $7 \mathrm{ng} / \mathrm{l}$ (Hilton and Thomas, 2003); in addition, it was detected with a median concentration of 21 $\mathrm{ng} / \mathrm{l}$ in the River Tyne, UK (Roberts and Thomas, 2006); nevertheless, it was not detected in the Elbe and Saale Rivers in Germany at any of the measured points (OSPAR, 2005).

The HC50 parameter contributes $59 \%$ to the impact variance of the antihypertensive receptor diltiazem. This parameter is of even greater concern, given that only 1 experimental EC50 value was found in the literature (Supplementary data, Table S5).

No abiotic degradation data are available. However, diltiazem is expected to be susceptible to indirect photolysis since it has double bonds and aromatic rings, and because it has chromophores that absorb at wavelengths $\mathrm{N} 290 \mathrm{~nm}$, it has the potential to be degraded by direct photolysis; therefore, the depletion of diltiazem in the aquatic environ- ment may be underestimated.

The HC50 parameter contributes $95 \%$ to the impact variance of the proton-pump inhibitor omeprazole. Moreover, only 1 experimental EC50 value was found in the literature (Supplementary data, Table S5). Very limited data on measurements of omeprazole in WWTP effluents are available in the literature (Rosal et al., 2010); nevertheless, it is one of the most widely prescribed pharmaceuticals. Omeprazole is expected to undergo hydrolysis in the environment due to the presence of functional groups that hydrolyse under environmental conditions, and it may also be susceptible to direct and indirect photolysis (DellaGreca et al., 2006); however, no experimental data were found in the literature.

In addition to the high contribution of $\mathrm{HC} 50$ to the variance of the macrolide antibiotic azithromycin's impact result (52.2\%) all EC50 values were estimated. The effluent concentration contributes $46.7 \%$ to the impact variance. The photodegradation of azithromycin was shown to be enhanced in the presence of nitrates and humic acids (Tong et al., 2011), which indicates the role of indirect photolysis in the persistence of this compound in the environment. However, indirect photodegradation was not included in the present study for this compound; therefore, the impact of azithromycin is most likely overestimated.

Concentrations of the hormone $17 \beta$-estradiol in WWTP effluents reported in the literature vary by 2 orders of magnitude, from 0.0007 to $0.0180 \mu \mathrm{g} / \mathrm{l}$ (Baronti et al., 2000; Clara et al., 2004). The variability of effluent concentration represents $63.6 \%$ of the impact variance. The HC50 parameter contributes $29.2 \%$ to the variance. Experimental acute EC50 values for 6 species were applied; however, the EC50 value for algae was estimated.

The diuretic bendroflumethiazide, the anti-inflammatories 5- aminosalicylic acid and ketorolac, and the lipid regulator clofibrate are discussed in the Supplementary data (Section 5).

\subsection{Additional considerations}

Table 1 summarises future research topics for the pharmaceuticals of greatest concern. These topics can be related to 3 issues: a) the fate of pharmaceuticals in WWTPs, b) substance-specific modelling parame- ters, and c) lack of spatial and time resolution models. The first topic includes compounds with very limited data on measurements or detection in WWTP effluents, such as tamoxifen or amitriptyline. These sub- stances should be subject to further monitoring in WWTPs, depending on geographical usage patterns, for more conclusive results. This catego- ry should also include compounds whose impact result would be most sensitive to variations of the emission concentration. Ideally, a comparatively well characterised drug from an impact perspective would account for low variance of output results due to environmental fate and transport modelling parameters, either estimated or experimental, and due to EEF characterisation. The uncertainty of its impact result, from a modelling perspective, would be related mainly to the variability of the concentration in WWTP effluents, depending on geographical and seasonal usage patterns, treatment technologies, and operation condi- tions. The focus of research for these compounds should be detailed eco- logical risk assessments possibly leading to research and development on the operation and design of WWTPs to improve the reduction of

Table 1

Research topics for pharmaceuticals of most concern. Three arrows denote a research topic of higher concern, two arrows denote a research topic of moderate concern, and one arrow denotes a research topic lower concern.

\begin{tabular}{|c|c|c|c|c|}
\hline & \multirow[t]{2}{*}{ Effluent } & \multirow[t]{2}{*}{ Ecotoxicological effect } & \multicolumn{2}{|l|}{ Parameter } \\
\hline & & & Abiotic degradation & Derivative \\
\hline $\begin{array}{l}\text { 17R-Fctradinl } \\
\text { 5-Aminnsalirvlir } \\
\text { Aminnnvrine } \\
\text { Amitrintvline }\end{array}$ & 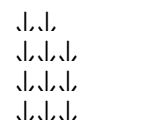 & 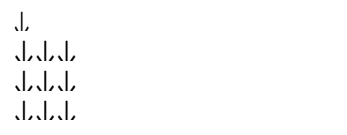 & 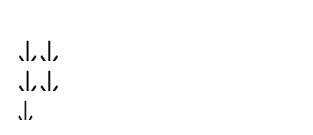 & 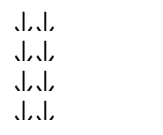 \\
\hline
\end{tabular}




\begin{tabular}{|c|c|c|c|c|}
\hline Azithromycin & $\downarrow \downarrow \downarrow$ & $\downarrow \downarrow \downarrow$ & $(\downarrow \downarrow)$ & $\downarrow \downarrow$ \\
\hline $\begin{array}{l}\text { Retaxolnl } \\
\text { Clntrimazole } \\
\text { Condeine } \\
\text { niazenam } \\
\text { Diltiazem } \\
\text { Flunxetine } \\
\text { Ketornlar } \\
\text { Mefenamic acid } \\
\text { nmenraznle } \\
\text { nxnrennlnl } \\
\text { Prnnranolnl } \\
\text { Tamnxifen } \\
\text { Tramadol }\end{array}$ & 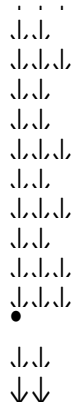 & 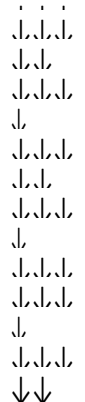 & 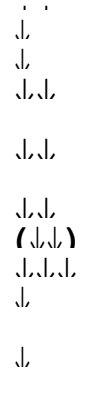 & 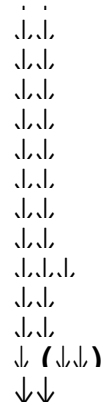 \\
\hline
\end{tabular}

a $\bullet$ : more than 10 peer-reviewed publications; $\downarrow$ : between 5 and 10 peer-reviewed publications; $\downarrow \downarrow$ : between 2 and 5 peer-reviewed publications; $\downarrow \downarrow \downarrow$ : only one peer-reviewed publication.

$\mathrm{b} \downarrow \downarrow$ : more than 3 acute EC50s covering 3 trophic levels; $\downarrow \downarrow: 3$ acute EC50s covering 3 trophic levels; $\downarrow \downarrow \downarrow$ : at least 1 estimated or extrapolated EC50.

c Number of possible abiotic degradation mechanisms not included in the assessment (hydrolysis, direct and indirect photolysis); ( $\downarrow)$ denotes a specific degradation pathway with some evidence of occurrence in the literature but with no data available.

d Number of possible degradation mechanisms generating derivatives (hydrolysis, photolysis and biodegradation); ( $\downarrow \downarrow)$ denotes a specific degradation pathway with evidence of

derivatives toxicity in the literature. 
the compounds' effluent concentrations. However, the compounds most sensitive to the emission concentration, such as diazepam or mefenamic acid, have other research priorities either because of limited data on their occurrence or incomplete modelling parameters.

The second issue includes drugs whose impact results are mostly sensitive to the uncertainty of substance-specific modelling parameters, such as degradation rates or partitioning coefficients, or to EEF characterisation. It also includes drugs whose impact result may be affected by modelling incompleteness, either from the lack of abiotic degradation data (such as for omeprazole or azithromycin) or from the exclusion of degradation products (such as for tamoxifen). These compounds should be subjected to further experimental research according to the most sensitive parameters because of a lack of precise knowledge regarding those parameters. The third issue, the lack of spa- tial and time resolution models, addresses the variability of landscape parameters, such as freshwater $\mathrm{pH}$ or $\left[{ }^{\bullet} \mathrm{OH}\right]$, and the seasonal variation of direct photolysis rates. However, for the compounds of greatest con- cern, only the spatial variability is somewhat significant, and only in the case of $\left[{ }^{\bullet} \mathrm{OH}\right]$. The large scale applied in the present study displays a great variety of landscape characteristics; nevertheless, the uncertainty regarding the HC50 parameter and the variability of the effluent concentration predominate in terms of the contribution of variance to the output results.

\subsection{Model limitations}

It should be noted that other sources of uncertainty not included in the Monte Carlo analysis may be important. Some have already been discussed above, such as the uncertainty of ecotoxicological data esti- mation, the extrapolation of endpoints, the lack of abiotic degradation data for several compounds, and the exclusion of abiotic and biotic derivatives of parent compounds. This last source of uncertainty may be relevant in the case of tamoxifen, as already mentioned; however, substances that do not appear in the ranking of compounds of most concern may have their comparative impact substantially increased by the inclusion of their derivative impact. For example, some researchers have suggested that the phototransformation products of triclosan, diclofenac or hydrochlorothiazide have a higher toxicity potential than their parent compounds (Han et al., 2000; Schmitt-Jansen et al., 2007). Nevertheless, the inclusion of phototransformation product impact is possible, if the chemical structures are identified, by applying the method proposed by van Zelm et al. (2010).

In addition, the uncertainty of the influence of $\mathrm{pH}$ on direct and indirect photolysis rates, the uncertainty of the application of a linear dose-response curve for the calculation of EEFs, and the lack of spatial variation of background impacts in the AMI method remain unclear. For example, for uncertainty of the influence of $\mathrm{pH}$ on the abiotic degradation, the literature data on the direct phototransformation of triclosan $\left(\mathrm{p} K_{\mathrm{a}}=8.1\right.$ ) applied in the present study are based on its anionic form (Tixier et al., 2002), which is the dominant photochemical degradation pathway. Therefore, by disregarding the influence of $\mathrm{pH}$ on the direct photolysis rate, the residence time of triclosan in the freshwater environment may be underestimated for lower $\mathrm{pH}$ values.

A first screening approach to deal with the uncertainty of speciation of an organic compound could be based on a uniformal distribution using the lowest and highest degradation rates amongst all the species involved in the speciation as the minimum and maximum. Therefore, quantum yields and experimental molar absorption coefficients in func- tion of the UV/VIS wavelength range of all the species involved must be experimentally obtained and applied to models that compute direct photolysis rates and half-lives of pollutants in the aquatic environment. A similar approach can be applied for indirect photolysis by obtaining experimental rate constants between chemical transients and all the chemical species involved in the speciation. 


\section{Conclusions}

Despite the high uncertainties of the pharmaceutical impact results, which range up to 12 orders of magnitude, and the model's limitations and parameter incompleteness, the outcome of the present study allows priorities to be set for further experimental testing. Several pharmaceu- tical compounds were identified as being of greatest concern, including 7 analgesics/anti-inflammatories, 3 B-blockers, 3 psychiatric drugs, and 1 each of 6 other therapeutic classes.

Notably, some pharmaceuticals identified as of greatest concern, such as tamoxifen, clotrimazole and oxprenolol, have rarely been inves- tigated previously with regard to their ecotoxicity, their occurrence in WWTPs, or their degradation in the environment. Theoretically, the relevant pharmaceuticals may be susceptible to abiotic degradation. However, in general, no experimental data are available; hence, the per- sistence of these pharmaceuticals in the freshwater compartment is es- timated to be comparatively higher than that of well-researched pharmaceuticals that were not included on the ranking of priority com- pounds, such as triclosan, diclofenac or ibuprofen.

Ecotoxicity data remain to be the most critical issue affecting impact or risk assessments of pharmaceuticals. The present assessment is based on only 3 data values for most of priority pharmaceuticals (only approximately $4 \%$ of these compounds have more than 3 EC50 values) that produced wide confidence limits. Moreover, approximately $58 \%$ of the pharmaceuticals of priority have at least 1 estimated or extrapo- lated EC50.

In short, this study identified several pharmaceuticals both for further WWTP monitoring and for testing their ecotoxicity and their persistence in the environment.

\section{Conflict of interest}

All the authors of manuscript don't have any actual or potential con- flict of interest including any financial, personal or other relationships with other people or organisations within three years of beginning the submitted work that could inappropriately influence, or be perceived to influence, theirwork.

\section{Acknowledgments}

Sérgio Alberto Morais is grateful to FCT-Fundação para a Ciência e a Tecnologia for a Ph.D. grant (SFRH/BD/64599/2009). This work was supported by the Foundation of Science and Technology (FCT) of the Portuguese Ministry of Science, Technology and Higher Education (MCTES), through project PTDC/AAG$\mathrm{TEC} / 2692 / 2012$, as well as by the Ecotech Sudoe project (SOE2/P1/E377) "LCA and Ecodesign International network for environmental innovation".
Appendix A. Supplementary data

Supplementary data to this article can be found online at http://dx. doi.org/10.1016/j.scitotenv.2014.04.082.

\section{References}

Aherne GW, Briggs R. The relevance of the presence of certain synthetic steroids in the aquatic environment. J Pharm Pharmacol 1989;41:735-6.

Alder AC, Schaffner C, Majewsky M, Klasmeier J, Fenner K. Fate of beta-blocker human pharmaceuticals in surface water: comparison of measured and simulated concentra- tions in the Glatt Valley Watershed, Switzerland. Water Res 2010;44:936-48.

Andreozzi R, Raffaele M, Nicklas P. Pharmaceuticals in STP effluents and their solar photodegradation in aquatic environment. Chemosphere 2003;50:1319-30.

Avdeef A. Absorption and drug development: solubility, permeability, and charged state.

Hoboken, N.J., USA: Wiley; 2003.

Baronti C, Curini R, D'Ascenzo G, Di Corcia A, Gentili A, Samperi R. Monitoring natural and synthetic estrogens at activated sludge sewage treatment plants and in a receiving river water. Environ Sci Technol 2000;34:505966. 

Barron L, Havel J, Purcell M, Szpak M, Kelleher B, Paull B. Predicting sorption of pharma- ceuticals and personal care products onto soil and digested sludge using artificial neural networks. Analyst 2009;134:663-70.

Besse J-P, Garric J. Human pharmaceuticals in surface waters: implementation of a prior- itization methodology and application to the French situation. Toxicol Lett 2008;176: 104-23.

Borgman O, Chefetz B. Combined effects of biosolids application and irrigation with reclaimed wastewater on transport of pharmaceutical compounds in arable soils. Water Res 2013;47:3431-43.

Carlsson C, Johansson A-K, Alvan G, Bergman K, Kühler T. Are pharmaceuticals potent environmental pollutants?: part I: environmental risk assessments of selected active pharmaceutical ingredients. Sci Total Environ 2006;364:67-87.

Christen V, Hickmann S, Rechenberg B, Fent K. Highly active human pharmaceuticals in aquatic systems: a concept for their identification based on their mode of action. Aquat Toxicol 2010;96:167-81.

Clara M, Strenn B, Ausserleitner M, Kreuzinger N. Comparison of the behaviour of selected micropollutants in a membrane bioreactor and a conventional wastewater treatment plant. Water Sci Technol 2004;50:29-36.

DellaGreca $M$, lesce MR, Previtera $L$, Rubino $M$, Temussi $F$, Brigante $M$. Degradation of lansoprazole and omeprazole in the aquatic environment. Chemosphere 2006;63: 1087-93.

DellaGreca $M$, lesce MR, Isidori M, Nardelli A, Previtera L, Rubino $M$. Phototransformation products of tamoxifen by sunlight in water. Toxicity of the drug and its derivatives on aquatic organisms. Chemosphere 2007;67:1933-9.

Doll TE, Frimmel FH. Fate of pharmaceuticalsphotodegradation by simulated solar UV-light. Chemosphere 2003;52:1757-69.

EC. Technical guidance document on risk assessment in support of Commission Directive 93/67/EEC on risk assessment for new notified substances, Commission Regulation (EC) No 1488/94 on risk assessment for existing substances and directive 98/8/EC of the European Parliament and the Council concerning the placing of biocidal products on the market. In: Comission E, editor. European Chemicals Bureau; 2003.

Escher Bl, Bramaz N, Richter M, Lienert J. Comparative ecotoxicological hazard assessment of beta-blockers and their human metabolites using a mode-of-action-based test battery and a QSAR approach. Environ Sci Technol 2006;40:7402-8.

Escher BI, Baumgartner R, Koller M, Treyer K, Lienert J, McArdell CS. Environmental toxicology and risk assessment of pharmaceuticals from hospital wastewater. Water Res 2011;45:75-92.

Fent K, Weston AA, Caminada D. Ecotoxicology of human pharmaceuticals. Aquat Toxicol 2006;76:122-59.

Franco A, Trapp S. Estimation of the soil-water partition coefficient normalized to organic carbon for ionizable organic chemicals. Environ Toxicol Chem 2008;27:19952004.

Fu W, Franco A, Trapp S. Methods for estimating the bioconcentration factor of ionizable organic chemicals. Environ Toxicol Chem 2009;28:1372-9.

Gómez MJ, Martínez Bueno MJ, Lacorte S, Fernández-Alba AR, Agüera A. Pilot survey mon- itoring pharmaceuticals and related compounds in a sewage treatment plant located on the Mediterranean coast. Chemosphere 2007;66:9931002.

Han KD, Bark KM, Heo EP, Lee JK, Kang JS, Kim TH. Increased phototoxicity of hydrochlo- rothiazide by photodegradation. Photodermatol Photoimmunol Photomed 2000;16: 121-4.

Hilton MJ, Thomas KV. Determination of selected human pharmaceutical compounds in effluent and surface water samples by high-performance liquid chromatographyelectrospray tandem mass spectrometry. J Chromatogr A 2003;1015:129-41.

Huijbregts $M$, Hauschild $M$, Jolliet $O$, Margni $M$, McKone $T$, Rosenbaum RK, et al. USEtox user manual version 1.01. USEtox Team; 2010.

Kasprzyk-Hordern B, Dinsdale RM, Guwy AJ. The removal of pharmaceuticals, personal care products, endocrine disruptors and illicit drugs during wastewater treatment and its impact on the quality of receiving waters. Water Res 2009;43:363-80.

Lam MW, Young CJ, Mabury SA. Aqueous photochemical reaction kinetics and transfor-mations of fluoxetine. Environ Sci Technol 2004;39:513-22.

Larsen HF, Hauschild M. Evaluation of ecotoxicity effect indicators for use in LCIA. Int J Life Cycle Assess 2007a;12:24-33.

Larsen HF, Hauschild M. GM-troph: a low data demand ecotoxicity effect indicator for use in LCIA. Int J Life Cycle Assess 2007b;12:79-91.

Larsen HF, Olsen SI, Hauschild M, Laurent A, Netune. New sustainable concepts and pro- cesses for optimization and upgrading municipal wastewater and sludge treatment. Work package 4 - assessment of environmental sustainability and best practice. Deliverable 4.2 methodology for including specific biological effects and pathogen aspects into LCA. http://www.euneptune.org/Publications\%20and\%20Presentations/ D4-2 NEPTUNE_Version_1-0.pdf, 2010. [Acessed 18th October 2013].

López-Serna R, Petrović M, Barceló D. Occurrence and distribution of multi-class pharmaceuticals and their active metabolites and transformation products in the Ebro River basin (NE Spain). Sci Total Environ 2012;440:280-9.

Maurer M, Escher BI, Richle P, Schaffner C, Alder AC. 
Elimination of $\beta$-blockers in sewage treatment plants. Water Res 2007;41:1614-22.

Mennigen JA, Martyniuk CJ, Crump K, Xiong H, Zhao E, Popesku J, et al. Effects of fluoxe- tine on the reproductive axis of female goldfish (Carassius auratus). Physiol Genomics 2008;35:273-82.

Morais SA, Delerue-Matos C, Gabarrell X. Accounting for the dissociating properties of organic chemicals in LCIA: an uncertainty analysis applied to micropollutants in the assessment of freshwater ecotoxicity. J Hazard Mater 2013a;248-249:461-8.
Morais SA, Delerue-Matos C, Gabarrell X, Blánquez P. Multimedia fate modeling and comparative impact on freshwater ecosystems of pharmaceuticals from biosolids- amended soils. Chemosphere 2013b;93(2):252-62.

Nabholz V, Mayo-Bean K. ECOSAR. U.S. Environmental Protection Agency; 2009.

OSPAR Commission. Hazardous substances series: OSPAR background document on clotrimazole. OSPAR Publication 1-904426-38-7; 2005 [2005/199, 2005, Acessed 18th October 2013, http://www.ospar.org/documents/dbase/publications/ p00595/

p00595_bd\%20on\%20clotrimazole\%20update\%202013.p df\&gt].

Payet J. Assessing toxic impacts on aquatic ecosystems in life cycle assessment (LCA). PhD Lausanne: École Polytechnique Fédérale de Lausanne; 2004.

Payet J. Assessing toxic impacts on aquatic ecosystems in LCA. Int J Life Cycle Assess 2005; 10:373.

Payet J, Jolliet $\mathrm{O}$. Comparative assessment of the toxic impact of metals on aquatic ecosys- tems: the AMI method. In: Dubreuil A, editor. Life-cycle assessment of metals: issues and research directions. (Proceedings of the International Workshop on Life-Cycle Assessment and Metals. Montreal, Canada. 15-17 April 2002). Pensacola, FL, USA: SETAC; 2005.

Quinn B, Gagné F, Blaise C. The effects of pharmaceuticals on the regeneration of the cnidarian, Hydra attenuata. Sci Total Environ 2008;402:62-9.

Radjenovic J, Petrovic M, Barcelo D. Fate and distribution of pharmaceuticals in wastewa- ter and sewage sludge of the conventional activated sludge (CAS) and advanced membrane bioreactor (MBR) treatment. Water Res 2009;43:831-41.

Roberts $\mathrm{PH}$, Thomas KV. The occurrence of selected pharmaceuticals in wastewater effluent and surface waters of the lower Tyne catchment. Sci Total Environ 2006; 356:143-53.

Rosal R, Rodríguez A, Perdigón-Melón JA, Petre A, GarcíaCalvo $E$, Gómez $M J$, et al. Occurrence of emerging pollutants in urban wastewater and their removal through biological treatment followed by ozonation. Water Res 2010;44:578-88.

Rosenbaum RK, Bachmann TM, Gold LS, Huijbregts MAJ, Jolliet $\mathrm{O}$, Juraske $\mathrm{R}$, et al. USEtox - the UNEP-SETAC toxicity model: recommended characterisation factors for human toxicity and freshwater ecotoxicity in life cycle impact assessment. Int J Life Cycle Assess 2008;13:532-46.

Sabourin L, Beck A, Duenk PW, Kleywegt S, Lapen DR, Li HX, et al. Runoff of pharmaceu- ticals and personal care products following application of dewatered municipal biosolids to an agricultural field. Sci Total Environ 2009;407:4596604.

Sanderson $\mathrm{H}$, Thomsen M. Ecotoxicological quantitative structure-activity relationships for pharmaceuticals. Bull 
Environ Contam Toxicol 2007;79:331-5.

Sanderson H, Johnson DJ, Reitsma T, Brain RA, Wilson CJ, Solomon KR. Ranking and prioritization of environmental risks of pharmaceuticals in surface waters. Regul Toxicol Pharmacol 2004;39:158-83.

Santos L, Araujo AN, Fachini A, Pena A, Delerue-Matos C, Montenegro M. Ecotoxicological aspects related to the presence of pharmaceuticals in the aquatic environment. J Hazard Mater 2010;175:45-95.

Schmitt-Jansen $M$, Bartels $P$, Adler $N$, Altenburger R. Phytotoxicity assessment of diclofenac and its phototransformation products. Anal Bioanal Chem 2007;387:1389-96.

Suárez S, Ramil M, Omil F, Lema JM. Removal of pharmaceutically active compounds in nitrifyingdenitrifying plants. Water Sci Technol 2005;52:9-14.

Tabak HH, Bunch RL. Steroid hormones as water pollutants. Dev Ind Microbiol 1970;41:735-6.

Tarazona JV, Escher BI, Giltrow E, Sumpter J, Knacker T. Targeting the environmental risk assessment of pharmaceuticals: facts and fantasies. Integr Environ Assess Manag 2010;6:603-13.

Tauxe-Wuersch A, De Alencastro LF, Grandjean D, Tarradellas J. Occurrence of several acidic drugs in sewage treatment plants in Switzerland and risk assessment. Water Res 2005;39:1761-72.

Ternes TA. Occurrence of drugs in German sewage treatment plants and rivers. Water Res 1998;32:324560.

Tixier C, Singer HP, Canonica S, Müller SR. Phototransfomation of ticlosan in surface waters: a relevant elimination process for this widely used biocide-laboratory studies, field measurements, and modeling. Environ Sci Technol 2002;36:3482-9.

Tong L, Eichhorn P, Pérez S, Wang $\mathrm{Y}$, Barceló D. Photodegradation of azithromycin in various aqueous systems under simulated and natural solar radiation: kinetics and identification of photoproducts. Chemosphere 2011;83:340-8.

U.N. Consolidated list of products whose consumption and or sale have been banned, withdrawn, severely restricted or not approved by governments: pharmaceuticals. New York: United Nations; 2003.

USEPA. BCFBAF. U.S. Environmental Protection

Agency; 2008a. USEPA. KOWWIN. U.S.

Environmental Protection Agency; 2008b.

USEPA. KOCWIN. U.S. Environmental Protection

Agency; 2009.

van Zelm R, Huijbregts MAJ, Harbers JV, Wintersen A, Struijs J, Posthuma L, et al. Uncertainty in msPAF-based ecotoxicological effect factors for freshwater ecosystems in life cycle impact assessment. Integr Environ Assess Manag 2007;3:e6-37.

van Zelm R, Huijbregts MAJ, van de Meent D. Transformation products in the life cycle impact assessment of chemicals. Environ Sci Technol
2010;44:1004-9.

Verlicchi P, Al Aukidy M, Zambello E. Occurrence of pharmaceutical compounds in urban wastewater: removal, mass load and environmental risk after a secondary treatment-a review. Sci Total Environ 2012;429:123-55.

Werner JJ, McNeill K, Arnold WA. Environmental photodegradation of mefenamic acid. Chemosphere 2005;58:1339-46.

Wick A, Fink G, Joss A, Siegrist $H$, Ternes TA. Fate of beta blockers and psycho-active drugs in conventional wastewater treatment. Water Res 2009;43:1060-74. 